
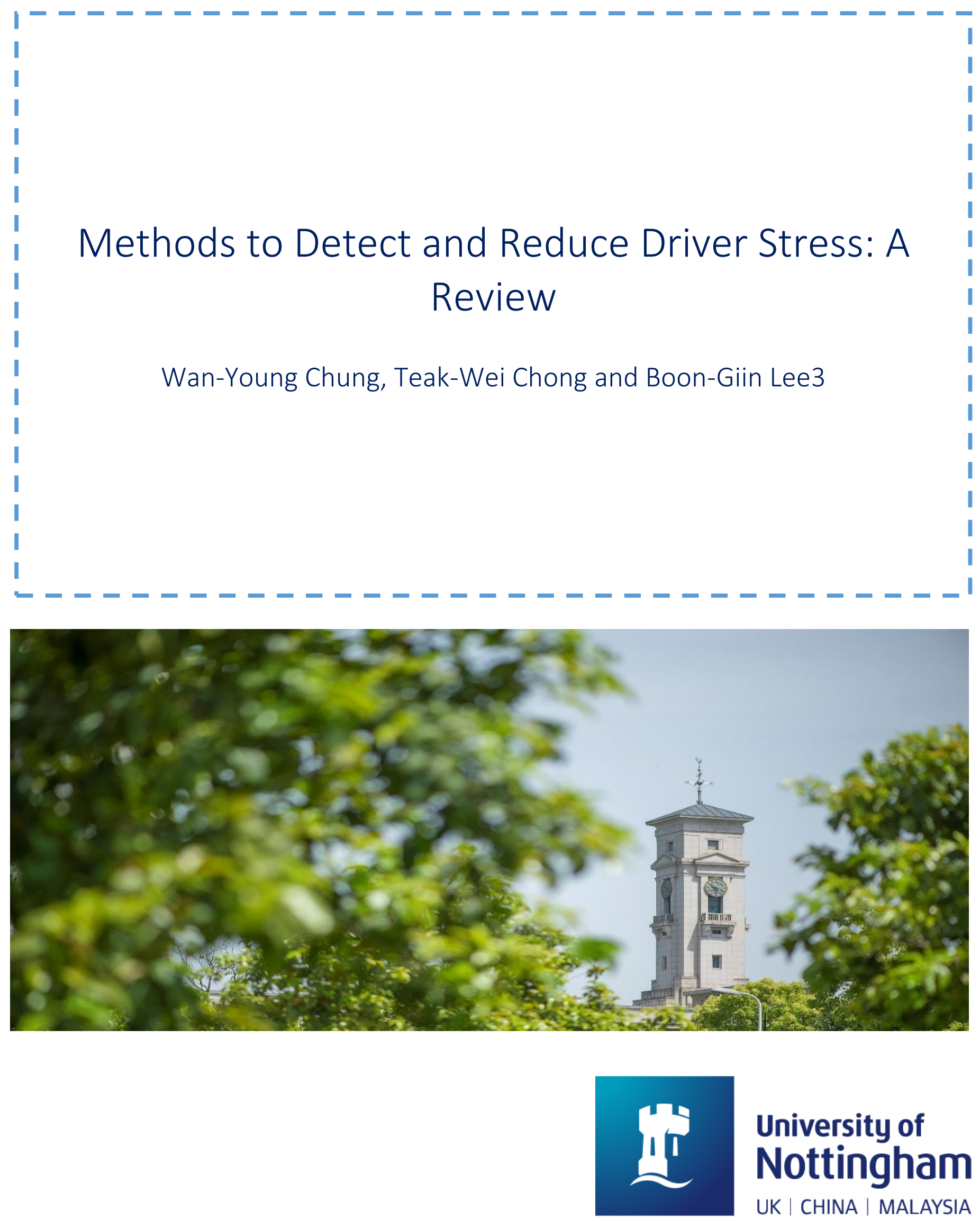

University of Nottingham 
School of Computer Science, Faculty of Science and Engineering, the University of Nottingham Ningbo China, Ningbo, 315100, China

First published 2019

Copyright 2019 Wan-Young Chung, Teak-Wei Chong and Boon-Giin Lee3

This work is made available under the terms of the Creative Commons Attribution 4.0 International License: http://creativecommons.org/licenses/by/4.0

The work is licenced to the University of Nottingham Ningbo China under the Global University Publication Licence:

https://www.nottingham.edu.cn/en/library/documents/researchsupport/global-university-publications-licence.pdf 


\title{
METHODS TO DETECT AND REDUCE DRIVER STRESS: A REVIEW
}

\author{
Wan-Young Chung ${ }^{1)}$, Teak-Wei Chong ${ }^{2)}$ and Boon-Giin Lee ${ }^{3)^{*}}$ \\ 11Department of Electronics Engineering, Pukyong National University, Busan 48513, Korea \\ 2Department of Electronics Engineering, Keimyung University, Daegu 42601, Korea \\ ${ }_{3}^{3}$ School of Computer Science, Faculty of Science and Engineering, The University of Nottingham Ningbo China, \\ Ningbo 315100, China
}

(Received 3 August 2018; Revised 5 March 2019; Accepted 19 March 2019)

\begin{abstract}
Automobiles are the most common modes of transportation in urban areas. An alert mind is a prerequisite while driving to avoid tragic accidents; however, driver stress can lead to faulty decision-making and cause severe injuries. Therefore, numerous techniques and systems have been proposed and implemented to subdue negative emotions and improve the driving experience. Studies show that conditions such as the road, state of the vehicle, weather, as well as the driver's personality, and presence of passengers can affect driver stress. All the above-mentioned factors significantly influence a driver's attention. This paper presents a detailed review of techniques proposed to reduce and recover from driving stress. These technologies can be divided into three categories: notification alert, driver assistance systems, and environmental soothing. Notification alert systems enhance the driving experience by strengthening the driver's awareness of his/her physiological condition, and thereby aid in avoiding accidents. Driver assistance systems assist and provide the driver with directions during difficult driving circumstances. The environmental soothing technique helps in relieving driver stress caused by changes in the environment. Furthermore, driving maneuvers, driver stress detection, driver stress, and its factors are discussed and reviewed to facilitate a better understanding of the topic.
\end{abstract}

KEY WORDS : Driver stress, Intelligent transportation, Transportation, Stress detection, Stress reduction

\section{INTRODUCTION}

In the second largest populated country, the United States of America, people spend an average of 46 min per day driving to school or work (Tripplett and Rosenbloom, 2015). In fact, the number of vehicles on the road increases by $100 \%$ every 10 to 15 years worldwide (Tripplett and Rosenbloom, 2015). The drastic increase in the number of vehicles, the driving population, and the number of road accidents globally is critical concern. It has also triggered technological advancements in the automobile industry that aid in providing road safety and reducing probable accidents (Meiring and Myburgh, 2015). Driver stress can cause the driver to make faulty and wrong decisions, which can be extremely dangerous (Westerman and Heigney, 2000; Kontogiannis, 2006). Besides its effect on road safety, driver stress can also affect a driver's personal health. According to Kompier and Di Martino (1995), prolonged stressful driving increases the risk of high blood pressure and other stress-related disorders significantly. Hence, methods to detect and reduce driver stress are discussed in this present paper. Several strategies for coping with driver stress were developed and introduced in

*Corresponding author. e-mail: boon-giin-lee@ nottingham. edu.cn the automobile industry (Stanton and Young, 2005; Reimer et al., 2010; T. C. Harrison Ford, 2017). These strategies are specially designed to avoid traffic accidents as well as improve the driving experience. The aim of this paper is to review the existing techniques for reducing and coping with driver stress.

This paper is organized as follows. Definition of stress and how the factors of driver stress are presented in the Section 2. In the following section, state-of-the-art methods for stress detection are categorized into four groups; then each category is presented and discussed. Section 3 shows two difference driving stress maneuvers that are widely used by researches, and their effect on driver stress is discussed. In Section 4, methods of driver stress reduction are presented in detail. In the last section, a conclusion and recommendations for future studies on driver stress detection and reduction are highlighted.

\section{DRIVER STRESS AND FACTORS}

Stress is a generally well-understood term that can be hard to define. Stress is a state of physical, psychological, or emotional strain experienced by a person when actual or perceived demands results in an elevated mobilization of resources in an attempt to cope with those demands (Lazarus and Folkman, 1984; The American Institute 


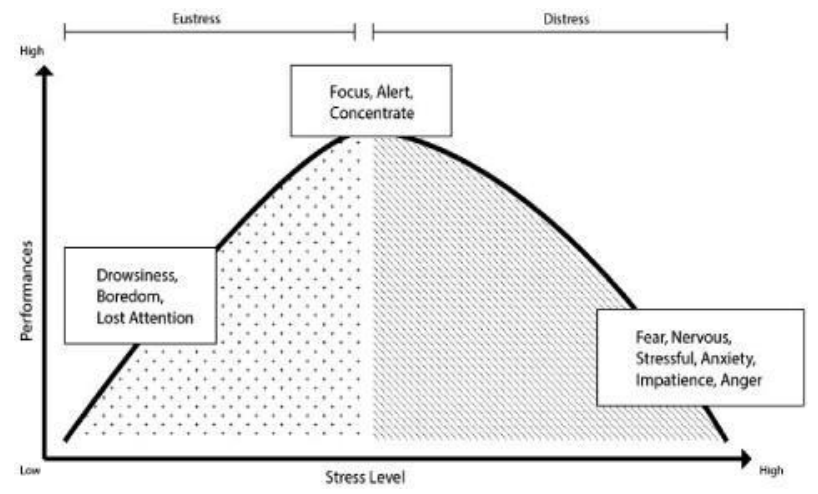

Figure 1. Relation between stress level and performance. The best performances occurs at the optimal stress point, which varies for different people (Healy and Picard, 2005).

Stress, 2017). High levels of mental workload are experienced when task demand approaches or exceeds the performer's capacity (Loft et al., 2007). Therefore, stress is often considered to be synonymous with a high cognitive workload. Similarly, stress is often accompanied by specific emotions such as anxiety (Hansen, 1996). From a psychological perspective, stress levels could be affected by personal cognitive and perceptual aspect (Tripplett and Rosenbloom, 2015). Humans tend to have some kind of internal representation of the outside world that may be changed by metabolic and memory processes (Koolhaas et al., 2011). However, stress is not always a negative experience and can also be classified as eustress and distress (Healy and Picard, 2005). As illustrated in Figure 1 , eustress is good stress as it motivates a person to have higher performance levels, whereas distress is an excessive demand or negative emotion that exceeds coping capacity or otherwise demotivates a person (Selye, 1976). Low levels of stress can lead to a state of boredom and drowsiness while driving, resulting in a loss of attention (The American Institute Stress, 2017). Although, driver drowsiness and fatigue can cause the driver to fall asleep, lose control of the wheel, and therefore impact safety, the focus of this paper is on elevated levels of driver stress. In this paper, driver stress refers to the demand levels or negative emotion that can lead to faulty decision-making or failure in attention (distraction) while driving.

Stress levels can be impacted by a variety of factors. For the purposes of this review, the key factors have been organized into four categories: the physical and mental condition of the driver, road and traffic conditions, vehicle condition, and external disturbances. Examples are provided in Table 1 with selected elaborations in the rest of this section.

Driving can involve highly dramatic maneuvering and urgencies, such as having to apply the emergency brake when the vehicle in front suddenly reduces its speed. Unpredictable situations can be frightening and highly dangerous. These unforeseen events may indirectly increase the driver's physical and mental stress. However, a driver's capability is defined by his driving experiences and skills as driving requires a good command over one's emotions, disposition, and particularly, unforeseen emergencies (Westerman and Heigney, 2000). Therefore, some drivers are not comfortable or confident while driving. Such drivers use extra effort to overcome physical and psychology obstacles (Wiesenthal et al., 2000).

Hill and Boyle (2007) suggested that driver stress is not only related to the driver's characteristics, but also to the driving environment. Road and traffic conditions significantly affect the driver stress levels according to Wiesenthal et al. (2000), who observed that driver stress is significantly higher on highly congested traffic roads as compared to low-congestion roads. Further, road width is one of the environmental factors that affects a driver's stress levels. Driving on a narrow and curvy road increase the driving workload (Schieß1, 2007).

Moreover, driving in bad weather conditions requires higher concentration and simultaneously burdens the driver's concentration. For example, drivers are subjected to higher workload while driving in heavy rain and foggy conditions (low visibility) as compared to driving on a clear sunny day (Hill and Boyle, 2007); the worse the weather condition, the higher the driving workload. In RiminiDoering et al. (2001) a foggy driving condition was simulated to induce fatigue and stress. The results proved that driving at night (low visibility) can be considered as one of the factors that affect a driver's stress level.

Passensgers may assist the driver through actions, such as navigating, talking, and warning the driver of approaching hazards. Good passengers assist drivers and reduce their workloads; however, some passengers become key stress factors. Regan and Mitsopoulos (2001) and Engström (2008) studies showed that passengers are good at assisting drivers while driving; however, they should remain silent to avoid disturbing the driver's concentration during highly stressful driving situations. Similarly, poorly designed driver assistance systems and navigation prompts that are delivered at inopportune times may annoy the driver (Reimer et al., 2010) and contribute to, rather than reduce, stress.

\section{STRESS DETECTION METHODS}

To accurately acquire and measure a driver's stress levels and observe changes under different driving situations respectively, numerous metrics to measure stress levels and driver workload have been proposed and executed. In general, four approaches are widely used by researchers in the advanced automobile industry. Table 2 provides summary of the driver stress detection methods and their limitations. Table 4 shows a list of sensors for stress detection. 
Table 1. Stress factors and examples.

\begin{tabular}{cl}
\hline Stress factor & \multicolumn{1}{c}{ Examples } \\
\hline Driver's physical and & Lack of sleep, driver fatigue (Kompier and Di Martino, 1995) \\
mental condition & Driving phobia and impatient \\
& Curved narrow roads (Schieß1, 2007) \\
Road and traffic conditions & Congestion and heavy traffic (Wiesenthal et al., 2000) \\
& Motorist disturbances \\
& Machine noise (Wiesenthal et al., 2000) \\
Engine malfunction \\
Vehicle condition & Passengers in the vehicle (Regan and Mitsopoulos, 2001; Engström, \\
& 2008) Gadgets (Mobile Phone) (Reimer et al., 2010) In-car smart \\
& applications (Navigation prompt) Weather condition (Low \\
& visibility, slippery road) (Rimini-Doering et al., 2001; Hill and \\
& Boyle, 2007; Hu et al., 2011) \\
\hline
\end{tabular}

3.1. Self-report Questionnaire Assessment

The self-report questionnaire was designed to focus on the driver's behavior in various driving situations and while carrying various tasks. The questionnaire studies the driver's behavior and his/her respective coping strategies. Accordingly, drivers react differently to different kinds of stressful events. Additionally, driver stress is the outcome of a combination of driver characteristics such as age, driving experience, and crash history (Reimer et al., 2010). Therefore, this information is important for the assessment. According to Hill and Boyle (2007), drivers with a history of crashes reported higher stress levels while driving. Drivers with a crash history are more likely to report travel anxiety (Mayou and Bryant, 2003) and suffer from post-traumatic stress disorder (Blanchard et al., 1996). Therefore, the driver behavior inventory (DBI) is widely used in many experiments. In DBI, driver stress is defined by five factors: i) driving aggression, ii) dislike of driving, iii) tension and frustration connected with successful or unsuccessful overtaking, iv) irritation when overtaken, and v) heightened alertness and concentration. A five-point Likert scale (Mcleod, 2017) $(0=$ Never, $1=$ Rarely, 2 = Occasionally, $3=$ Frequently, $4=$ Very Frequently) is usually associated with a self-report inventory to describe and measure each inventory item. In this questionnaire, all assessment questions are correlated to each other. Stressful events in everyday life are mentioned as one of the factors as well.

Most self-report questionnaires are separated into two types; pre-experiment assessments and post-experiment assessments. Pre-experiment assessments are carried out to observe the driver's condition before the driving simulation and real-world driving studies. In some cases, only postsimulation assessment data is collected for analysis. To obtain the assessment data simultaneously, researchers can collect verbal reports. In Mehler et al. (2016) and Reimer et al. (2010), participants were asked to subjectively rate their stress level verbally on a scale of 0 to 10 where 0 is not stressed at all and 10 is totally stressed during the experiment; whereas, in Hennessy and Wiesenthal (1999), participants were interviewed over a cellular telephone to report their driver stress levels. The driving stress inventory (DSI) (Costin et al., 2012), stress arousal checklist (SACL) (Matthews et al., 1996), and Dundee stress state questionnaire (DSSQ) (Matthews et al., 1999) were designed to assess driver stress levels, whereas the NASA task load index (NASA-TLX) (Hart and Staveland, 1988; De Waard, 1996) and driving activity load index (DALI) (Pauzié, 2008a, 2009) are widely used to obtain workload ratings in different simulation experiments. Each questionnaire has its own aim. A few sets of questionnaires could be provided in a single experiment for specific research purposes. For example, in Funke et al. (2007), participants were asked to complete the DSI before the experiment and DSSQ was conducted pre- and post-task. DSI is used to assess the driver's vulnerability to stress (i.e. aggression; dislike of driving; hazard monitoring; thrill seeking; fatigue proneness) with scores scaled from 0-100. Workload items within the DSSQ are incorporated with NASA-TLX to observe the degree of mental, physical and temporal demand, as well as, the performance, effort, and frustration associated with a task through a six 10-point rating scale. Therefore, Pauzie (2008a, 2009) developed a specific rating scale to access mental workload while driving.

Brookhuis and De Waard (2002) have discussed the use of mental workload assessments and other subjective qualifications. Brookhuis and De Waard (2002) mentioned that subjective measures and scales are rather common in traffic and transport research studies. Nevertheless, predictive validity, timing and memory, and context and consciousness are important and crucial for correct assessment of the self-report questionnaire. This especially occurs in the traffic and transport field, where the 
experiments are carried out in dynamic situations and extremely variable conditions (Brookhuis and De Waard, 2002).

\subsection{Physiological Measures}

Physiological sensors are used to detect the human body's physiological changes, such as brain activation, electrodermal activity (skin conductance or galvanic skin response (GSR)), heart rate, heart rate variability (HRV), muscle tension, and respiration rate (Healy and Picard, 2005; Yamakoshi et al., 2008; Mehler et al., 2009; Munla et al., 2015). For instance, electroence-phalography (EEG) is widely used by researchers to detect human brain waves; the electrocardiograph $(\mathrm{EKG})$ is used to record heart rate and skin temperature; photoplethysmography (PPG) to measure changes in peripheral blood flow; electromyography (EMG) to measures muscle activity; and electrodermal sensors are used to measure the electrical conductance of the skin which changes largely as a function of sweat gland activity. For stress detection, as we unable to monitor the internal representation of perception of a driver, we have to rely on a subtle and detailed analysis of physiological measurement (Koolhaas et al., 2011). Physiological measurements for stress detection are proposed by Wijsman et al. (2011) and Sun et al. (2010) In Horvath (1978), an experimental comparison of the psychological stress evaluator and GSR was executed.

According to Reimer et al. (2010) and Westerman and Heigney (2000), stress from driving is associated with an increase in heart rate and blood pressure. Bakker et al. (2011) monitored human stress using the GSR sensors. Castin et al. (2012) observed stress using electrocardiogram (ECG) signals. Physiological sensors can record data during the driving experiment (Coughlin et al., 2009). They monitor physiological changes, and could potentially provide drivers with useful reference information about their body's conditions while driving (Coughlin et al., 2009). Healy and Picard (2005) mentioned that real-time driver stress can be detected, after a training segment has been completed, by the use of machine learning. GSR, HRV, and methods to measure heart rate were suggested as the best real-time correlates of stress (Healy and Picard, 2005). Each physiological sensor has its own advantages and limitations. Sensor artifacts or coding metrics can cause latency issues. For instance, anticipatory electromyography (EMG) has been measured in the laboratory at $30 \mathrm{~ms}$ (Barniv et al., 2005); however, skin conductivity latency was of the order of $1.4 \mathrm{~s}$ (Lockhart, 1972). Although, skin temperature can show a decrease with stress, it can also show delays and directional shifts that can exceed 60 s. Moreover, GSR signals vary among individuals and on a daily basis, even for the same individual (Bakker et al., 2011). Therefore, Kurniawan et al. (2013) suggested that other forms of measurements, instead of relying only on GSR-based detection of stress, are needed to obtain more reliable data. Therefore, researchers now detect stress via multi-physiological sensors (Healy et al., 1999; Healy and Picard, 2005). In a stress detection experiment conducted by Healy et al. (1999), four types of physiological signals were recorded, namely, skin conductance, heart activity, respiration, and muscle activity. Moreover, Mehler et al. (2012) found that individuals whose measurements vary will show the most reactivity and suggested that hybrid detection systems that consider multiple measures might be more sensitive than those dependent on a single measure.

Advanced technologies enable researchers to design and develop non-invasive sensors to acquire data accurately without any contact with the driver. Use of several noninvasive sensors to collect physiological data to avoid obstructing the driver while driving has been proposed (Vavrinsky et al., 2012; Mizuno and Hiep, 2013). These sensors often come with the vehicle and, therefore, no extra setup to activate the sensors is needed.

\subsubsection{Challenges of sensor system design}

Despite the debut of a non-invasive sensor system that successfully avoids obstructing to the driver, three key elements of sensor system design should be considered, namely, size and dimension, accuracy, and power consumption. Ideal sensor systems should be lightweight and tiny in size to reduce the intrusiveness, but also highly accurate with a low power consumption. However, in reality, a tiny sensor system could be highly costly owing to the difficulty of its production process. Additionally, accuracy and power consumption are usually directly related, i.e., high performance sensor system often requires a considerable amount power consuming for data processing and analysis. From the perspective of driver stress detection sensor system design, driver safety should be prioritized; therefore, tiny and non-invasive sensor systems are recommended.

However, there are some physiological sensors (PPG, GSR, and skin temperature sensors) that have to be attached to the participants' body directly to acquire reliable signals (Jimenez, 2013). Although wearable sensors may cause drivers to experience some encumbrance in normal activity, the dimension and size of the sensors could be sufficiently optimized to lower the degree of intrusiveness.

Furthermore, physiological sensor signals are often corrupted owing to electrode contact noise, motion artifacts, power line interference, baseline drift, contraction, etc. (Munla et al., 2015). Specifically during driving, motion artifacts can be contaminated easily by movement and other interferences. To avoid signal noise and interferences that could potentially mislead the results and accuracy, filtering of raw signals and further signal processing is vital during the preprocessing stage because sets of raw captured data can be incomprehensible (Munla et al., 2015). To remove the noisy signal caused by motion artefacts, Healy (2009) suggested two solutions: track 
activity and only attempt affective analysis during periods of relative rest or attempt to model the effects of motion and factor them out.

\subsection{Driving Behavior Monitoring}

Lee et al. (2017) mentioned that driver stress detection is achievable by monitoring driving behavior, and Lanatà et al. (2015) reported that the autonomic system (ANS) and driving style changed under driving stimulations with incremental stress levels. Stressful and non-stressful driving events are statistically detected by dynamic steering wheel correction and vehicle velocity (Lanatà et al., 2015). Instead of observing the driver's body conditions, driving behavior monitoring systems observe his/her driving performance. Lee et al. (2017) developed a wearable pair of gloves that has a 9-DOF inertial motion unit (IMU) sensor to calculate steering wheel motion (SWM). Moreover, by implementing a multi-sensor integrated system, vehicle movement parameters on roads with different conditions can be recorded and analyzed. In most of the studies, the GPS unit, cameras, and ranging sensors, such as the ultrasonic sensor and laser scanner unit, were installed in the vehicle to observe driving behavior (Schieß1, 2007; Takeda et al., 2009; Meiring and Myburgh, 2015). Figure 2 shows an example of how the sensors were installed in the vehicle (Ohn-Bar et al., 2014). In steady driving conditions, the driver aims to consistently maintain a constant velocity (Lanatà et al., 2015). A preprogrammed camera is used to execute lane recognition to observe the vehicle's locus to monitor driving behavior (Schieß1, 2007). A laser scanner and radar sensor are used to capture data from the surrounding environment and detect the distance between the vehicle and obstacles (Schieß1, 2007). A computer is required to direct the sensors capturing vital information (Takeda et al., 2009). ViewCar (Schießl, 2007), NU-Drive (Meiring and Myburgh, 2015), and Uyanik (Takeda et al., 2009) are three examples of intelligent vehicle systems embedded in real vehicles to observe driving behavior in the real world. They can monitor the turning patterns of the steering wheel

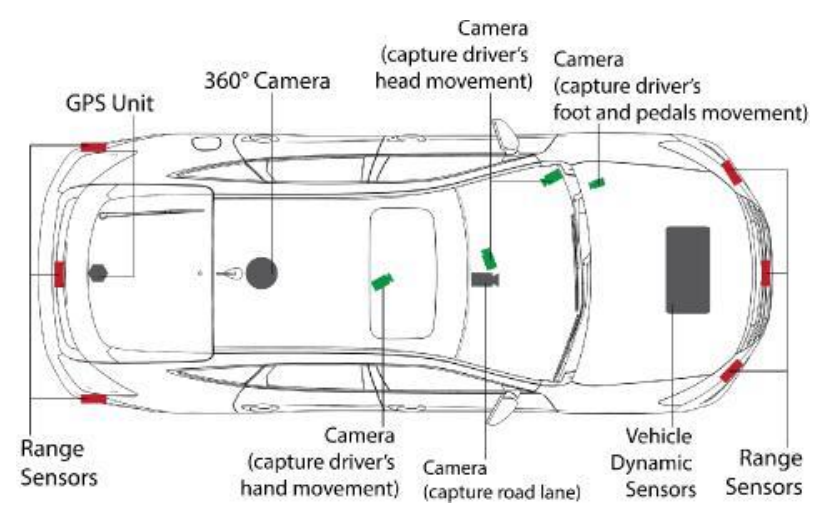

Figure 2. Shows the positions of each sensor installed in vehicle. and recognize lanes and accelerating patterns. All those data are recorded and analyzed to detect and measure the driver's stress arousal state.

\subsection{Visual-based and Speech Detection}

Physiological sensors have to be attached to the driver's body directly, whereas visual-based sensors are installed on the vehicle rather than on driver's body. Visual-based sensors have a greater potential of measuring driver stress and mental workload as they are non-invasive and can assess real-time and automated workload (Or and Duffy, 2007). For instance, visual-based thermography to detect facial skin temperature (Yamakoshi et al., 2008) and pupil dilation have been implemented in several driver stress studies (Pedrotti et al., 2014; Baltaci and Gokcay, 2016). In a study conducted by Or and Duffy (2007), nose and forehead skin temperature were captured via thermography. Nose skin temperature is found to respond to stimuli, i.e., the higher the stimuli, the greater the decrease in nose skin temperature (Or and Duffy, 2007). Pedrotti et al. (2014) proved that the pupil diameter (PD) increases during stressful events. For the acquisition and analysis of the PD parameters, six different steps were taken from preprocessing to classification (Lee et al., 2017). PD changes have been found to be very sensitive in response to stress in the laboratory under controlled lighting conditions, however, the technique has several limitations under realworld driving scenarios as PD reacts to light intensity as well as stress stimuli. Gao et al. (2014) introduced a method for detecting driver's stress via the analysis of facial expressions that can be captured by a NIR-camera. However, illumination and occlusion become an issue in data collection for facial features (Fernández et al., 2016). Therefore, computer vision technology is applied for accurate facial detection and data correction. Gao et al. (2014) proposed a data normalization step that is applied using the $3 \mathrm{D}$ cylindrical head model to increase the accuracy and decrease the impact of driver pose mismatch due to variations in camera setup and driver position.

Alternatively, Yin et al. (2007) determined driver stress by analyzing the changes in pitch in a subject's speech. A set of speech data for stress detection has been presented by Hansen (1996). Boril et al. (2010) and Fernandez et al. (2003) found that driver stress could be observed by speech. Boril et al. (2010) recommended that subject complete several tasks by verbally answering into the voice recorder while driving. The collected speech data were then subjected to signal processing for further analysis and emotional stress classification. Driver stress detection by speech was found to be obstructive for the driver while driving, as the driver needs to perform additional tasks in order to do the required speech recording. Fernandez et al. (2003) suggested drivers perform a secondary task by answering while driving in a simulator. The additional secondary task was a distraction in this case as well.

As the raw data for facial skin temperature, PD, and 
Table 2. Summary of stress detection methods.

\begin{tabular}{|c|c|c|c|}
\hline Refs. & Methods & Examples & Limitations \\
\hline $\begin{array}{l}\text { (Hart and Staveland, 1988; } \\
\text { Matthews et al., 1996; } \\
\text { Westerman and Heigney, } \\
\text { 2000; Kontogiannis, 2006) }\end{array}$ & $\begin{array}{l}\text { Self-report } \\
\text { questionnaire } \\
\text { assessment }\end{array}$ & $\begin{array}{l}\text { Driving Stress Inventory (DSI), } \\
\text { Driving Behavior Inventory (DBI), } \\
\text { Stress Arousal Checklist (SACL), } \\
\text { Dundee Stress State Questionnaire } \\
\text { (DSSQ), NASA Task Load Index } \\
\text { (NASA-TLX) }\end{array}$ & $\begin{array}{l}\text { Questionnaire is commonly } \\
\text { known as subjective. A specific } \\
\text { purpose set of question and } \\
\text { variety have to be implemented. }\end{array}$ \\
\hline $\begin{array}{l}\text { (Healey et al., 1999; } \\
\text { Mehler et al., 2009) }\end{array}$ & $\begin{array}{l}\text { Physiological } \\
\text { measures }\end{array}$ & $\begin{array}{l}\text { Photoplethysmography (PPG) sensor, } \\
\text { Galvanic Skin Response (GSR) sensor, } \\
\text { Electrocardiogram (ECG) sensor, } \\
\text { Electroencephalography (EEG) sensor }\end{array}$ & $\begin{array}{l}\text { Problematic influence on accu- } \\
\text { racy and sensitivity along with } \\
\text { being intrusive. }\end{array}$ \\
\hline $\begin{array}{l}\text { (Alvarsson et al., 2010; } \\
\text { Lanatà et al., 2015; } \\
\text { Meiring and Myburgh, } \\
\text { 2015) }\end{array}$ & $\begin{array}{l}\text { Driving } \\
\text { behavior } \\
\text { monitoring }\end{array}$ & $\begin{array}{l}\text { Lane recognition, steering movement, } \\
\text { braking and accelerating recorder }\end{array}$ & $\begin{array}{l}\text { Vehicle types, driver experience } \\
\text { and road conditions are dynamic } \\
\text { and affecting the data acquisi- } \\
\text { tion. }\end{array}$ \\
\hline $\begin{array}{l}\text { (Matthews et al., 1996; } \\
\text { Yamakoshi et al., 2008; an } \\
\text { Kurniawan } \text { et al., 2013) de }\end{array}$ & $\begin{array}{l}\text { Visual-based } \\
\text { d speech } \\
\text { tection }\end{array}$ & $\begin{array}{l}\text { Facial temperature changes, } \\
\text { pupil dilation and speech }\end{array}$ & $\begin{array}{l}\text { Visual-based: easily disturbed } \\
\text { when occlusion or illumination } \\
\text { changes appear. } \\
\text { Speech: distraction for driver } \\
\text { during the journey as a second- } \\
\text { ary task. }\end{array}$ \\
\hline
\end{tabular}

speech are not suitable for analysis directly. The collected data and extracted features are subject to signal processing, such as normalization or noise cancelation, which is important for speech detection (Hansen, 1996). Furthermore, several classification techniques have been performed using several classifier and machine-learning algorithms (Lee et al., 2017). Neural network was applied in Alvarsson et al. (2010), while a SVM classifier was applied in Fernandez et al. (2003).

\section{DRIVING STRESS MANEUVERS- A REVIEW}

To detect and collect necessary data on driving stress, two different assessment approaches are commonly used: driving simulations and real-world driving tasks. Sahayadhas et al. (2012) adapted a low-level simulator with basic driving simulator equipment, facilities, and multiscreens, while Pradhan et al. (2005) adapted an immersive driving simulator using a real vehicle and high-quality realistic graphics that are projected onto big screens; and English (2009) utilized a highly immersive 360-degree professional driving simulator that mimics all driving circumstances inside a 360-degree motion simulation space. In the section below, their purpose and limitations are discussed and reviewed. Although driving simulators in the current market offer a realistic driving experience and allow researchers to reproduce driving situations consistently for each participant during the experiments, from the perspective of investigating the driver behaviors, it is unsafe and unethical to mimic certain driving situations, such as road accidents and road safety violations, while driving in the real world. Hence, in an experiment conducted by Yamaguchi and Sakakima (2007), stress was evaluated by using driving simulators, while Parsons et al. (1998) conducted an experiment using realworld driving tasks. Both driving stress maneuvers served different study purposes. A virtual and a real driving task were compared by Sena et al. (2014), who used similar driving scenarios for both driving task, and a lower variant of the heart rate was found in a fixed base simulator but not in the real driving task. Reimer and Mehler (2011), found that absolute heart rate values were higher during real-world driving tasks but showed very similar relative increases in heart rate during both the simulator and real-world driving task in response to increased levels of cognitive demand. For facial skin temperature, Or and Duffy (2007) found that the driving simulator resulted in a higher level of driver stress and a greater drop in nose temperature than the realworld driving task. The studies highlighted above observed and showed physiological changes in both driving simulator and real-world driving.

However, in a laboratory, a large degree of control can be exerted over the subject's behavior and better results can be expected (Healy, 2009). While driving on the road, the subjects were expected to encounter unpredictable stress stimuli; Reimer and Mehler (2011) found that absolute levels of heart rate and skin conductance were lower for participants in the simulator than they were for participants in real-world driving scenarios. However, the relative increases in heart rate were very similar in both, the simulator and real-world driving tasks. Thus, simulation is 
Table 3. Driving stress maneuvers- advantages and limitations.

\begin{tabular}{llll}
\hline Refs. & Methods & Advantages & Limitations \\
\hline $\begin{array}{l}\text { (Kontogiannis, 2006; } \\
\begin{array}{l}\text { Pauzié, 2009; Son } \text { et al., } \\
\text { 2011) }\end{array}\end{array}$ & $\begin{array}{l}\text { Real-world } \\
\text { driving task }\end{array}$ & $\begin{array}{l}\text { Real driving experience; enables } \\
\text { interaction with other drivers on } \\
\text { road. }\end{array}$ & $\begin{array}{l}\text { Unsafe and unethical to perform cer- } \\
\text { tain driving situation, such as accident } \\
\text { and road violation. Driving situation is } \\
\text { not reproducible. }\end{array}$ \\
$\begin{array}{llll}\text { (Mackay } \text { et al., 1978; } \\
\begin{array}{l}\text { Yamaguchi and Sakakima, } \\
\text { 2007; Hu } \text { et al., 2011) }\end{array}\end{array}$ & $\begin{array}{l}\text { Able to mimic any road situation } \\
\text { simulator }\end{array}$ & $\begin{array}{l}\text { Driving experience may different in } \\
\text { lower cost. Driving situation is } \\
\text { consistent for every participants }\end{array}$ & $\begin{array}{l}\text { leal-world driving and has reported } \\
\text { with different physiological parameters } \\
\text { recorded. }\end{array}$ \\
\hline
\end{tabular}

Table 4. List of sensors for stress detection.

\begin{tabular}{|c|c|c|}
\hline No. & Sensor & Refs. \\
\hline 1. & Electrocardiogram (ECG) & (Costin et al., 2012; Lanatà et al., 2015) \\
\hline 2. & Electromyogram (EMG) & (Healy and Picard, 2005; Vavrinsky et al., 2012) \\
\hline 3. & $\begin{array}{l}\text { Skin conductivity } \\
\text { Electrodermal activation (EDA) } \\
\text { Galvanic skin response (GSR) }\end{array}$ & (Healy et al., 1999; Yamakoshi et al., 2008; Bakker et al., 2011) \\
\hline 4. & Respiration sensor & (Healy et al., 1999; Lanatà et al., 2015) \\
\hline 5. & Psychogalvanic reflex & (Lockhart, 1972) \\
\hline 6. & Pressure sensors & (Lockhart, 1972) \\
\hline 7. & Pupil dilation (camera sensor) & (Pedrotti et al., 2014; Baltaci and Gokcay, 2016) \\
\hline
\end{tabular}

very useful for assessing relative levels of stress associated with different tasks. However, it is not as good at showing what the absolute values of various physiological measures might be under real-world driving conditions. Moreover, Healy (2009) found that the human system might respond differently to stimuli, so a model of history and persondependent specifications are necessary for accurate signal interpretation. However, differences in maneuvers and reallife driving were investigated by Reimer and Mehler (2011), who found that driving simulators can produce convincing and reliable results as well. Most importantly, Wang et al. (2010) stated that a fixed-base driving simulator provides a safe and structured environment for evaluating performance on several tasks. Table 3 demonstrates the advantages and limitations of the virtual and real-world driving tasks. Although driving simulatiors have several limitations, they still provided reliable and valid data. In most cases, driver stress detection experiments are carried out under highly dangerous situations to trigger and observe driver stress. Therefore, a driver simulator is highly recommended for future driver stress investigation studies.

\section{STRESS REDUCTION AND RECOVERY}

Stress reduction and recovery is defined as the act of relieving stress arousal to an optimal level to improve driving performance and potentially increase driver wellness. This paper targets driver stress; therefore, the coping strategies mentioned in this paper are only designed for drivers. Driver stress reduction and recovery techniques ameliorate driver stress via several aspects, such as assisting with driving at a slow-pace in high-congestion traffic, or autopilot navigation systems that reduce the driver's workload. There are numerous stress reduction and recovery strategy systems that have been developed by vehicle manufacturers and researchers (Stanton and Young, 2005; Reimer et al., 2010). In this section, stress reduction and recovery techniques are categorized into three major categories: (1) driver assistance systems, (2) notification alerts, and (3) environmental soothing. Table 5 lists these three categories, as well as methods for stress reduction, stress detection, and the results; limitations are discussed in the section below.

\subsection{Driver Assistance Systems}

Driving assistance systems are a collection of systems and subsystems that assist or take over part of driver's task to reduce or even eliminate driver errors, and enhance efficiency (Brookhuis et al., 2001). However, this paper focused on driving tasks in high-stress situations for the purpose of reducing the driver's workload and stress levels. Such systems may employ several types of ranging sensors, such as an ultrasonic sensor, a radar sensor, and a laser scanner installed in the vehicle to capture data from the surrounding environment (Reimer et al., 2016). 
Therefore, driving behavior monitoring techniques are often applied in driver assistance systems to observe the surrounding conditions. Once the surrounding environment has been captured and analyzed, the system will prompt a set of steps or actively assist the driver in performing the task easily (T. C. Harrison Ford, 2017). For example, active park assist (APA) is an automation system that assists drivers with parking (Reimer et al., 2016; Active Park Assist, 2017), while adaptive cruise control (ACC) is based on a range sensor and distance control system (Stanton and Young, 2005). The control system has authority over the throttle and brakes to switch between speed and headway control in response to the range sensor. As reported, driver assistance systems mentioned above assisted the driver in performing stressful driving tasks effectively and reduced driver stress level relatively (Reimer et al., 2016). Reimer et al. (2016) confirmed that driver stress is reduced while using the driver assistance system and that the average heart beats is significantly reduced by $12.6 \mathrm{bpm}$ when using the APA system. Moreover, there are numerous vehicle assistance systems available, such as active city stop (ACS) (T. C. Harrison Ford, 2017), lane keeping aid
(Ford Europe, 2011), and ACC (Stanton and Young, 2005). Different driver assistance systems provide different types of assistance in different driving situations; for example, the ACS is suitable for slow speeds in high city traffic areas (T. C. Harrison Ford, 2017), whereas the ACC targets stressful driving events (Stanton and Young, 2005). Nevertheless, the ACC system is reported to have successfully reduced driver mental workload and improved driving performance in multiple dimensions (Ma and Kaber, 2005).

\subsection{Notification Alert}

A notification alert system is a warning system that notifies the driver when a hazard is detected (Howard, 2017). There are two types of potential notification alert systems: driver physiological condition notification alert system and road situation notification alert system. Driver will be notified once the his/her stress levels are susceptible to be high. The notification message may request the driver to reduce his/ her driving speed and drive safely. On the other hand, road situation notification alert systems warn the driver when a hazard is detected. A series of ranging sensors are installed

Table 5. Driving stress reduction and recovery techniques.

\begin{tabular}{|c|c|c|c|c|c|}
\hline Refs. & Stress reduction & Methods & Stress stimuli & Detections & Results \\
\hline $\begin{array}{l}\text { Reimer et al. } \\
(2016)\end{array}$ & $\begin{array}{l}\text { Driver } \\
\text { assistance } \\
\text { systems }\end{array}$ & $\begin{array}{l}\text { Active Park } \\
\text { Assist (APA) }\end{array}$ & Car parking & $\begin{array}{l}\text { Self-report assess- } \\
\text { ment and physiologi- } \\
\text { cal signal }\end{array}$ & $\begin{array}{l}\text { Stress level signifi- } \\
\text { - cantly lower (12.6 } \\
\text { bpm lower) }\end{array}$ \\
\hline $\begin{array}{l}\text { T. C. Harrison } \\
\text { Ford (2017) }\end{array}$ & $\begin{array}{l}\text { Driver } \\
\text { assistance } \\
\text { systems }\end{array}$ & $\begin{array}{l}\text { Active City } \\
\text { Stop (ACS) }\end{array}$ & $\begin{array}{l}\text { Traffic jam, high } \\
\text { congestion traffic }\end{array}$ & - & $\begin{array}{l}\text { Assist driver and } \\
\text { reduce driver's } \\
\text { workload }\end{array}$ \\
\hline $\begin{array}{l}\text { Ma and Kaber } \\
(2005), \text { Stanton } \\
\text { and Young (2005) }\end{array}$ & $\begin{array}{l}\text { Driver } \\
\text { assistance } \\
\text { systems }\end{array}$ & $\begin{array}{l}\text { Adaptive Cruise } \\
\text { Control (ACC) }\end{array}$ & $\begin{array}{l}\text { High-demand } \\
\text { driving situations }\end{array}$ & $\begin{array}{l}\text { Dundee Stress State } \\
\text { Questionnaire } \\
\text { (DSSQ) }\end{array}$ & $\begin{array}{l}\text { Alleviate stress and } \\
\text { workload in high- } \\
\text { demand driving } \\
\text { situations }\end{array}$ \\
\hline $\begin{array}{l}\text { Reimer et al. } \\
(2010)\end{array}$ & $\begin{array}{l}\text { Notification } \\
\text { alert }\end{array}$ & $\begin{array}{l}\text { Cross Traffic } \\
\text { alert (CTA) }\end{array}$ & $\begin{array}{l}\text { Backing out from } \\
\text { parking }\end{array}$ & $\begin{array}{l}\text { Self-report assess- } \\
\text { ment and physiologi- } \\
\text { cal signal }\end{array}$ & $\begin{array}{l}\text { Warn drivers during } \\
\text { - hazards }\end{array}$ \\
\hline $\begin{array}{l}\text { Wijsman et al. } \\
\text { (2011) }\end{array}$ & $\begin{array}{l}\text { Notification } \\
\text { alert }\end{array}$ & $\begin{array}{l}\text { Lane Departure } \\
\text { Warning (LDW) }\end{array}$ & Long journey & - & $\begin{array}{l}\text { Audible warning, } \\
\text { visual and haptics } \\
\text { feedback warning to } \\
\text { notify driver }\end{array}$ \\
\hline $\begin{array}{l}\text { Wiesenthal et al. } \\
(2000)\end{array}$ & $\begin{array}{l}\text { Environmental } \\
\text { soothing }\end{array}$ & $\begin{array}{l}\text { Listen to pre- } \\
\text { ferred music }\end{array}$ & $\begin{array}{l}\text { High congestion } \\
\text { traffic }\end{array}$ & $\begin{array}{l}\text { Driving Behavior } \\
\text { Inventory-General } \\
\text { (DBI-Gen) }\end{array}$ & $\begin{array}{l}\text { Music constrain the } \\
\text { stress arousal level }\end{array}$ \\
\hline Jimenez (2013) & $\begin{array}{l}\text { Environmental } \\
\text { soothing }\end{array}$ & $\begin{array}{l}\text { Driver seat } \\
\text { massage }\end{array}$ & Driving on road & $\begin{array}{l}\text { Physiological signal } \\
\text { (Heart rate and } \\
\text { respiration rate) }\end{array}$ & $\begin{array}{l}\text { Relief on driver's } \\
\text { tension }\end{array}$ \\
\hline $\begin{array}{l}\text { Coughlin et al. } \\
(2009)\end{array}$ & $\begin{array}{l}\text { Environmental } \\
\text { soothing }\end{array}$ & $\begin{array}{l}\text { Natural-domi- } \\
\text { nated road view }\end{array}$ & $\begin{array}{l}\text { Nature-dominated } \\
\text { and artifact-domi- } \\
\text { nated road view }\end{array}$ & $\begin{array}{l}\text { Physiological signal } \\
\text { (facial EMG, ECG, } \\
\text { and blood pressure) }\end{array}$ & $\begin{array}{l}\text { Quicker recovered } \\
\text { from stress }\end{array}$ \\
\hline $\begin{array}{l}\text { Alvarsson et al. } \\
(2010)\end{array}$ & $\begin{array}{l}\text { Environmental } \\
\text { soothing }\end{array}$ & Nature sound & $\begin{array}{l}\text { Mental arithmetic } \\
\text { task }\end{array}$ & $\begin{array}{l}\text { Physiological } \\
\text { signal }\end{array}$ & $\begin{array}{l}\text { Stress recovered } \\
\text { quicker }\end{array}$ \\
\hline
\end{tabular}


in the vehicle to collect road situation data. The lane departure warning (LDW) system is a lane recognition system that detects driving behavior (Howard, 2017). A warning notification is activated to warn the driver when his or her vehicle is moving past the boundaries of the lane (Jadhav and Jadhav, 2015). Image processing and signal processing techniques are applied in the system to perform measurements. Additionally, laser scanners and ultrasonic sensors are widely used to detect and measure the distance between the vehicle and surrounding obstacles. Notifications are prompted if the vehicle approaches an obstacle. Both road situation and driver physiological state alert systems have been proven to improve a driver's situational awareness and reduce driver stress effectively while operating the vehicle. Reimer et al. (2010) reported that a majority of the participants are reported to have a better performance while backing out of a parking space with limited visibility by activating the cross traffic aid (CTA) system.

\subsection{Environment Soothing}

Environmental soothing is a therapy-like system that mainly focuses on alleviating the driver's physiological stress by altering the in-vehicle environmental condition. To detect driver stress, physiological sensors are often used to monitor the driver's mental and physical status. Further, signal processing and machine-learning algorithms are often used to detect and measure the driver's stress level. Once high-stress level is detected, an environment-soothing application is launched to relieve driver stress without any disturbances to the driver. For example, an intelligent car seat has been proposed as a solution for driver stress by Innovation Europe, Faurecia Automobile Seating. The intelligent car seat is an environment soothing system embedded in the car seat (Stock, 2015). The seat actively measures and monitors the driver's physiological status. Respiration and heart rates are analyzed by a designed algorithm to detect driver stress and energy level (Stock, 2015). The system is embedded seamlessly in the vehicle without causing any disturbance to the driver. Once the system detects the driver is in a high-stress state, a relaxation massage and warm ventilation equipped inside the driver seat are activated to soothe the driver (Stock, 2015). On the other hand, music therapy is known as one of the potential methods for reducing driver stress. Wiesenthal et al. (2000) observed that listening to preferred music decreases heart rate and reduce stress while driving in highly congested traffic. A smart music player that is able to recognize the driver's identity and select customized, driver-preferred music could help reduce driver stress. In other words, environmental soothing systems create and provide a comfortable driving environment to alleviate the driver's mental and physiological stress.

5.4. Limitations of Stress Reduction Techniques As reported by Reimer et al. (2010), some drivers face difficulty with these systems because of their unfamiliarity with new technologies, and, hence, find it difficult to follow the instructions suggested by the smart alert system. The drivers need to completely trust the new driver assistance systems to confidently utilize the system and be assisted (Reimer et al., 2010). Meanwhile, notification alerts may not always effectively reduce driver stress as drivers are allowed to use or ignore the notification (Matthews and Desmond, 2001) and inappropriate notifications could induce, rather than reduce, stress (Reimer et al., 2010). For instance, in a comparison study between APA and CTA conducted by Reimer et al. (2010), participants were uncertain if the CTA technology was active or not because it is only overtly presented a notification when a warning was present. Further, CTA assessment also reported an issue of false and missed alarms (Reimer et al., 2010). Warning systems with $0 \%$ failure detection are most likely unrealistic; therefore, accuracy and user's acceptance of a systems is crucial (Reimer et al., 2010). Although driver stress reduction systems are still under development and, a fully specific driver stress reduction system is yet to be released, many advanced driver assistance systems (ADAS) are equipped to aid and assist drivers during their daily drives. Notification systems can trigger negative emotions in drivers under certain situations (Reimer et al., 2010; Abdic et al., 2016). On the other hand, environment soothing techniques alter the driver emotions by adjusting invehicle surroundings. To generalize the environmental soothing technique for the masses is challenging, as it has been specially designed to cater to all aspects of the drivers' preferences and can be customized by the users.

\section{CONCLUSION}

This paper discussed the methods of detecting driver stress, including (1) self-report questionnaires, (2) physiological measures, (3) driving behavior monitoring, and (4) visualand speech-based detection, and also highlighted their advantages and limitations. Self-report questionnaire were found to be subjective; however, the reported physiological measures produced consistent and reliable results. Therefore, researchers are advised to multiple methods in a study to detect driver stress in order to acquire high-reliable result. Stress detection systems and hardware design are some of the key factors that need to be considered. Noninvasive sensors are highly recommended owing to the driver safety issue. An intrusive or second task for a driver during stress detection could cause a deadly traffic tragedy. A great stress detection and reduction system should be embedded in the vehicle seamlessly without asking the driver to perform additional tasks. Meanwhile, several stress reduction methods have been proposed by researchers. Stress reduction methods have been grouped into three categories, namely, (1) notification alerts, (2) driver assistance systems, and (3) environmental soothing 
techniques. Each of the stress reduction methods target to different driver stress stimuli. User friendliness is one of the major factors determining the use of an advanced driver assistance system. Effectively reducing the driver's mental and physical workload while driving is the most important consideration for the development of systems that aim to reduce driver stress.

Nowadays, people are seeking heathier and happier lives. Driver stress reduction technologies not only aid in road safety but also have the potential to provide pleasant trips for drivers and road users daily. A stress reduction enabled smart vehicle that allows the driver or the passengers to relax during a journey will soon be released. Hence, to design an intelligent driving embedded system for driver stress detection and reduction, non-invasive physiological sensors and environmental soothing technique are highly recommended. The key advantage of applying non-invasive physiological sensors and environmental soothing techniques is both of them are nonintrusive to the driver and alter driver stress levels seamlessly. Furthermore, researchers are advised to consider the user interface and user experience associated with these systems to allow the driver to fully utilize the designed system.

ACKNOWLEDGEMENT-This work was supported by MidCareer Researher Program through an NRF grant funded by the Korean Government (MSIT) (No. NRF-2016R1A2B4015818), Korea.

\section{REFERENCES}

Abdic, I., Fridman, L., McDuff, D., Marchi, E., Reimer, B. and Schuller, B. (2016). Driver frustration detection from audio and video in the wild. KI 2016: Advances in Artificial Intelligence: 39th Annual German Conf. AI, Klagenfurt, Austria.

Active Park Assist (2017). Ford. https://owner.ford.com/ how-tos/vehicle-features/convenience-and-comfort/ active-park-assist.html

Alvarsson, J. J., Wiens, S. and Nilsson, M. E. (2010). Stress recovery during exposure to nature sound and environmental noise. Int. J. Environmental Research and Public Health 7, 3, 1036-1046.

Bakker, J., Pechenizkiy, M. and Sidorova, N. (2011). What's your current stress level? Detection of stress patterns from GSR sensor data. Proc. IEEE 11th Int. Conf. Data Mining Workshops, Vancouver, Canada.

Baltaci, S. and Gokcay, D. (2016). Stress detection in human-computer interaction: Fusion of pupil dilation and facial temperature features. Int. J. HumanComputer Interaction 32, 12, 956-966.

Barniv, Y., Aguilar, M. and Hasanbelliu, E. (2005). Using EMG to anticipate head motion for virtual-environment applications. IEEE Trans. Biomedical Engineering 52, 6, 1078-1093.
Blanchard, E. B., Hickling, E. J., Taylor, A. E., Loos, W. R., Forneris, C. A. and Jaccard, J. (1996). Who develops PTSD from motor vehicle accidents?. Behaviour Research and Therapy 34, 1, 1-10.

Boril, H., Sadjadi, S. O., Kleinschmidt, T. and Hansen, J. H. (2010). Analysis and detection of cognitive load and frustration in drivers' speech. Proc. Eleventh Annual Conf. Int. Speech Communication Association, Chiba, Japan.

Brookhuis, K. A., De Waard, D. and Janssen, W. H. (2001). Behavioural impacts of advanced driver assistance systems - An overview. European J. Transport and Infrastructure Research 1, 3, 245-253.

Brookhuis, K. A. and De Waard, D. (2002). On the assessment of (mental) workload and other subjective qualifications. Ergonomics 45, 14, 1026-1030.

Costin, R., Rotariu, C. and Pasarica, A. (2012). Mental stress detection using heart rate variability and morphologic variability of EeG signals. Proc Int. Conf. and Exposition on Electrical and Power Engineering, Iasi, Romania.

Coughlin, J. F., Reimer, B. and Mehler, B. (2009). Driver Wellness, Safety \& the Development of an Awarecar. AgeLab, Massachusetts Institute of Technology, Cambridge, Massachusetts, USA.

De Waard, D. (1996). The Measurement of Drivers' Mental Workload. Groningen University. Traffic Research Center. Groningen, the Netherlands.

English, A. (2009). Toyota’s $£ 30$ Million Driving Simulator Review. The Telegraph. http:// www.telegraph.co.uk/motoring/road-safety/6598418/ Toyotas-30-million-driving-simulator-review.html

Engström, I. (2008). Young Drivers and Their Passengers Crash Risk and Group Processes. Ph. D. Dissertation. Linköping University. Linköping, Sweden.

Fernández, A., Usamentiaga, R., Carús, J. L. and Casado, R. (2016). Driver distraction using visual-based sensors and algorithms. Sensors 16, 11, 1805.

Fernandez, R. and Picard, R. W. (2003). Modeling drivers' speech under stress. Speech Communication 40, 1-2, 145-159.

Ford Europe (2011). Ford Focus- Lane Keeping Aid. https://www.youtube.com/watch?v=1_mUyQmxJQY

Funke, G., Matthews, G., Warm, J. S. and Emo, A. K. (2007). Vehicle automation: A remedy for driver stress?. Ergonomics 50, 8, 1302-1323.

Gao, H., Yüce, A. and Thiran, J. P. (2014). Detecting emotional stress from facial expressions for driving safety. Proc. IEEE Int. Conf. Image Processing (ICIP), Paris, France.

Hart, S. and Staveland, L. (1988). Development of a multidimensional workload rating scale: Results of empirical and theoretical research. Human Mental Workload, 52, 139-183.

Hansen, H. L. (1996). Analysis and compensation of speech under stress and noise for environment 
robustness in speech recognition. Speech Communication 20, 1-2, 151-173.

Healey, J., Seger, J. and Picard, R. (1999). Quantifying driver stress: Developing a system for collecting and processing bio-metric signals in natural situations. Biomedical Sciences Instrumentation, 35, 193-198.

Healy, J. A. and Picard, R. W. (2005). Detecting stress during real-world driving using physiological sensors. IEEE Trans. Intelligent Transportation Systems 6, 2, 156-166.

Healey, J. A. (2009). Affect detection in the real world: Recording and processing physiological signals. Proc. 3rd Int. Conf. Affective Computing and Intelligent Interaction and Workshops, Amsterdam, the Netherlands.

Hennessy, D. A. and Wiesenthal, D. L. (1999). Traffic congestion, driver stress, and driver aggression. Aggressive Behavior: Official J. Int. Society for Research on Aggression 25, 6, 409-423.

Horvath, F. (1978). An experimental comparison of the psychological stress evaluator and the galvanic skin response in detection of deception. J. Applied Psychology 63, 3, 338-344.

Howard, B. (2017). What is lane departure warning, and how does it work?. Extreme Tech. http:// www.extremetech.com/extreme/165320-what-is-lanedeparture-warning-and-e. how-does-it-work

$\mathrm{Hu}$, J. B., Li, A. and Wang, W. L. (2011). Analysis on driver's driving workload in different weather conditions. J. Beijing University of Technology 37, 4.

Hill, J. D. and Boyle, L. N. (2007). Driver stress as influenced by driving maneuvers and roadway conditions. Transportation Research Part F: Traffic Psychology and Behaviour 10, 3, 177-186.

Jadhav, P. and Jadhav, U. (2015). Lane departure warning system. Int. J. Computer Applications, 975, 8887.

Jimenez, M. (2013). Physiological Sensor: Electronic Theses and Dissertations, Paper 689.

Kompier, M. A. and Di Martino, V. (1995). Review of bus drivers' occupational stress and stress prevention. Stress Medicine 11, 1, 253-262.

Kontogiannis, T. (2006). Patterns of driver stress and coping strategies in a Greek sample and their relationship to aberrant behaviors and traffic accidents. Accident Analysis \& Prevention 38, 5, 913-924.

Koolhaas, J. M., Bartolomucci, A., Buwalda, B. D., De Boer, S. F., Flügge, G., Korte, S. M., Meerlo, P., Murison, R., Olivier, B., Palanza, P. and Richter-Levin, G. (2011). Stress revisited: A critical evaluation of the stress concept. Neuroscience \& Biobehavioral Reviews 35, 5, 1291-1301.

Kurniawan, H., Maslov, A. V. and Pechenizkiy, M. (2013). Stress detection from speech and galvanic skin response signals. Proc. 26th IEEE Int. Symp. Computer-Based Medical Systems, Porto, Portugal.

Lanatà, A., Valenza, G., Greco, A., Gentili, C., Bartolozzi,
R., Bucchi, F., Frendo, F. and Scilingo, E. P. (2015). How the autonomic nervous system and driving style change with incremental stressing conditions during simulated driving. IEEE Trans. Intelligent Transportation Systems 16, 3, 1505-1517.

Lazarus, R. S. and Folkman, S. (1984). Stress, Appraisal, and Coping. Springer. New York, USA.

Lee, D. S., Chong, T. W. and Lee, B. G. (2017). Stress events detection of driver by wearable glove system. IEEE Sensors J. 17, 1, 194-204.

Lockhart, R. A. (1972). Interrelations between amplitude, latency, rise time, and the Edelberg recovery measure of the galvanic skin response. Psychophysiology 9, 4, 437442 .

Loft, S., Sanderson, P., Neal, A. and Mooi, J. M. (2007). Modeling and prediciting mental workload in en-route air traffic control: Critical review and broader implications. Human Factor: J. Human Factors and Ergonomics Society 49, 3, 376-399.

Ma, R. and Kaber, D. B. (2005). Situation awareness and workload in driving while using adaptive cruise control and a cell phone. Int. J. Industrial Ergonomics 35, 10, 939-953.

Mackay, C., Cox, T., Burrows, G. and Lazzerini, T. (1978). An inventory for the measurement of self- reported stress and arousal. British J. Social and Clinical Psychology 17, 3, 283-284.

Matthews, G., Desmond, P. A., Joyner, L., Carcary, B. and Gilliland, K. (1996). Validation of the driver stress inventory and driver coping questionnaire. Proc. Int. Conf. Traffic and Transport Psychology, Valencia, Spain.

Matthews, G., Joyner, L., Gilliland, K., Campbell, S., Falconer, S. and Huggins, J. (1999). Validation of a comprehensive stress state questionnaire: Towards a state big three. Proc. Personality Psychology in Europe, Ghent, Belgium.

Matthews, G. and Desmond, P. A. (2001). Stress and driving performance: Implications for design and training. Human Factors in Transportation. Stress, Workload and Fatigue. Lawrence Erlbaum Associates Publishers. Mahwah, New Jersey, USA.

Mayou, R. and Bryant, B. (2003). Consequences of road traffic accidents for different types of road user. Injury 34, 3, 197-202.

Mcleod, S. (2017). Likert Scale. Simply Psychology. http:/ /www.simplypsychology.org/likert-scale.html

Mehler, B., Reimer, B., Coughlin, J. and Dusek, J. (2009). Impact of incremental increases in cognitive workload on physiological arousal and performance in young adult drivers. Transportation Research Record: J. Transportation Research Board 2138, 1, 6-12.

Mehler, B., Reimer, B. and Coughlin, J. F. (2012). Sensitivity of physiological measures for detecting systematic variations in cognitive demand from a working memory task: An on-road study across three age groups. Human Factors 54, 3, 396-412. 
Mehler, B., Kidd, D., Reimer, B., Reagan, I., Dobres, J. and McCartt, A. (2016). Multimodal assessment of onroad demand of voice and manual phone calling and voice navigation entry across two embedded vehicle systems. Ergonomics 59, 3, 344-367.

Meiring, G. A. M. and Myburgh, H. C. (2015). A review of intelligent driving style analysis systems and related artificial intelligent algorithms. Sensors 15, 12, 3065330682.

Mizuno, N. and Hiep, N. M. (2013). An adaptive filtering technique for driver's heart rate monitoring through vibration signal by seat-embedded piezoelectric sensors. IFAC Proc. Volumes 46, 11, 647-652.

Munla, N., Khalil, M., Shahin, A. and Mourad, A. (2015). Driver stress level detection using HRV analysis. Proc. Int. Conf. Advances in Biomedical Engineering (ICABME), Beirut, Lebanon.

Ohn-Bar, E., Tawari, A., Martin, S. and Trivedi, M. M. (2014). Predicting driver maneuvers by learning holistic features. IEEE Intelligent Vehicles Symp. Proc., Dearborn, Michigan, USA.

Or, C. K. and Duffy, V. G. (2007). Development of a facial skin temperature-based methodology for nonintrusive mental workload measurement. Occupational Ergonomics 7, 2, 83-94.

Parsons, R., Tassinary, L. G., Ulrich, R. S., Hebl, M. R. and Grossman-Alexander, M. (1998). The view from the road: Implications for stress recovery and immunization. J. Environmental Psychology 18, 2, 113-140.

Pauzié, A. (2008a). Evaluating driver mental workload using the driving activity load index (DALI). Proc. European Conf. Human Interface Design for Intelligent Transport Systems, Berlin, Germany.

Pauzié, A. (2008b). A method to assess the driver mental workload: The driving activity load index (DALI). IET Intelligent Transport Systems 2, 4, 315-322.

Pauzié, A. (2009). Method to evaluate driver's workload in real road context. Proc. Int. Conf. Digital Human Modeling, San Diego, California, USA.

Pedrotti, M., Mirzaei, M. A., Tedesco, A., Chardonnet, J. R., Mérienne, F., Benedetto, S. and Baccino, T. (2014). Automatic stress classification with pupil diameter analysis. Int. J. Human-Computer Interaction 30, 3, 220-236.

Pradhan, A. K., Hammel, K. R., DeRamus, R., Pollatsek, A., Noyce, D. A. and Fisher, D. L. (2005). Using eye movements to evaluate effects of driver age on risk perception in a driving simulator. Human Factors 47, 4, 840-852.

Regan, M. A. and Mitsopoulos, E. (2001). Understanding Passenger Influences on Driver Behaviour: Implications for Road Safety and Recommendations for Countermeasure Development (No. 180).

Reimer, B., Mehler, B. and Coughlin, J. F. (2010). An evaluation of driver reactions to new vehicle parking assist technologies developed to reduce driver stress.
Cambridge: New England University Transportation Center, Massachusetts Institute of Technology.

Reimer, B. and Mehler, B. (2011). The impact of cognitive workload on physiological arousal in young adult drivers: A field study and simulation validation. Ergonomics 54, 10, 932-942.

Reimer, B., Mehler, B. and Coughlin, J. F. (2016). Reductions in self-reported stress and anticipatory heart rate with the use of a semi-automated parallel parking system. Applied ergonomics, 52, 120-127.

Rimini-Doering, M., Manstetten, D., Altmueller, T., Ladstaetter, U. and Mahler, M. (2001). Monitoring driver drowsiness and stress in a driving simulator. Proc. 1st Int. Driving Symp. Human Factors in Driver Assessment, Training and Vehicle Design, Iowa, USA.

Sahayadhas, A., Sundaraj, K. and Murugappan, M. (2012). Detecting driver drowsiness based on sensors: A review. Sensors 12, 12, 16937-16953.

Schieß1, C. (2007). Stress and strain while driving. Proc. European Conf. Transport Research Institutes, 1-11.

Selye, H. (1976). Stress without distress. Psychopathology of Human Adaption, 137-146.

Sena, P., Fiorentino, A., D'Amore, M. and Fusco, B. M. (2014). Road scenario and driver stress level: An HRV study in both virtual and real environments. Proc. Transport Research Arena (TRA) 5th Conf.: Transport Solutions from Research to Deployment, Paris, France.

Son, J., Mehler, B., Lee, T., Park, Y., Coughlin, J. and Reimer, B. (2011). Impact of cognitive workload on physiological arousal and performance in younger and older drivers. Proc. 6th Int. Driving Symp. Human Factors in Driver Assessment, Training, and Vehicle Design, Iowa, USA.

Stanton, N. A. and Young, M. S. (2005). Driver behaviour with adaptive cruise control. Ergonomics 48, 10, 12941313.

Stock, M. (2015). Intelligent Car Seat Detects Driver's Stress Level: Reuters. http://www.reuters.com/article/uscar-technology/intelligent-car-seat-detects-drivers-stresslevel-idUSKCNORN11P20150923

Sun, F. T., Kuo, C., Cheng, H. T., Buthpitiya, S., Collins, P. and Griss, M. (2010). Activity-aware mental stress detection using physiological sensors. Proc. Int. Conf. Mobile Computing, Applications, and Services, Santa Clara, California, USA.

Takeda, K., Erdogan, H., Hansen, J. and Abut, H. eds. (2009). In-vehicle Corpus and Signal Processing for Driver Behavior. Springer-Verlag New York. New York, USA.

Tripplett, T. and Rosenbloom, S. (2015). American Driving Survey: Methodology and Year 1 Results. AAA Foundation, Washington.

Vavrinsky, E., Tvarozek, V., Gaspierik, P., Stopjakova, V., Donoval, M. and Teleka, P. (2012). Design of noninvasive setup for car driver biomonitoring. Procedia Chemistry, 6, 203-210. 
Wang, Y., Mehler, B., Reimer, B., Lammers, V., D'Ambrosio, L. A. and Coughlin, J. F. (2010). The validity of driving simulation for assessing differences between in-vehicle informational interfaces: A comparison with field testing. Ergonomics 53, 3, $404 \square$ 420.

Westerman, S. J. and Heigney, D. (2000). Individual differences in driver stress, error and violation. Personality and Individual Differences 29, 5, 981[998.

T. C. Harrison Ford (2017). What is Ford Active City Stop?. http://www.tch.co.uk/about/why-choose-ford/ active-city-stop

The American Institute Stress (2017). What is Stress? http://www.stress.org/what-is-stress

Wiesenthal, D. L., Hennessy, D. A. and Totten, B. (2000). The influence of music on driver stress. J. Applied Social Psychology, 30, $1709 \llbracket 1719$.

Wijsman, J., Grundlehner, B., Liu, H., Hermens, H. and Penders, J. (2011). Towards mental stress detection using wearable physiological sensors. Proc. Annual Int. Conf. IEEE Engineering in Medicine and Biology Society, Boston, Massachusetts, USA.

Yamaguchi, M. and Sakakima, J. (2007). Evaluation of driver stress in a motor-vehicle driving simulator using a biochemical marker. J. Int. Medical Research 35, 1, $91 \square 100$.

Yamakoshi, T., Yamakoshi, K., Tanaka, S., Nogawa, M., Park, S. B., Shibata, M., Sawada, Y., Rolfe, P. and Hirose, Y. (2008). Feasibility study on driver's stress detection from differential skin temperature measurement. Proc. IEEE Engineering in Medicine and Biology Society Annual Conf., Vancouver, Canada.

Yin, B., Ruiz, N., Chen, F. and Khawaja, M. A. (2007). Automatic cognitive load detection from speech features. Proc. 19th Australasian Conf. ComputerHuman Interaction: Entertaining User Interfaces, Adelaide, Australia.

Publisher's Note Springer Nature remains neutral with regard to jurisdictional claims in published maps and institutional affiliations. 